\title{
THE EFFECT OF ADDITION OF METFORMIN TO CLOMIPHENE CITRATE IN INDUCTION OF OVULATION FOR FEMALES WITH POLYCYSTIC OVARY SYNDROME
}

\author{
By \\ Mohamed A. Abd El-Al, Mohamed K. Mostafa, and Mohamed I. \\ Farahat \\ Department of Obstetrics and Gynecology, Faculty of Medicine, Al-Azhar University \\ Corresponding author: Mohamed A. Abdel-Al, Mobile: 01030246800 \\ E-mail: Mohammedabdelnasser.s@gmail.com
}

\begin{abstract}
Background: Clomiphene citrate is considered first line therapy for ovulation induction for women with polycystic ovary syndrome (PCOS) and infertility the benefits of metformin on insulin sensitivity have been demonstrated in non-diabetic women with PCOS.

Objective: Comparing the efficacy of Clomiphene citrate + Metformin, and Clomiphene citrate alone in treatment of anovulation.

Patients and Methods: Sixty patients were included in this study and were divided into two equal groups: The first group received (Clomiphene citrate for induction of ovulation starting from day 2 of the cycle for 5 days in a dose of $100 \mathrm{mg} /$ day and Metformin 500 $\mathrm{mg}$ tablets twice daily; while the second group received only Clomiphene citrate for induction of ovulation starting from day 2 of the cycle for 5 days with a dose of $100 \mathrm{mg} /$ day.

Results: Both lines of treatment were effective in treatment of PCOS patients without statistically significant difference between Clomiphene citrate + Metformin group, and Clomiphene citrate group as regard ovulation rate. There was a statistically significant decrease in oligomenorrhea after treatment in comparison to their values before treatment in both groups.
\end{abstract}

Conclusion: Both CC+Metformin, and CC alone were effective in treatment of infertility in PCOS patients.

Key Words: Infertility, PCOS, Clomiphene citrate, Metformin, Anovulation.

\section{INTRODUCTION}

Polycystic ovary syndrome (PCOS) is one of the most common causes of anovulatory infertility and affects $4-7 \%$ of women (Dennett and Simon, 2015).

It is by far the most common cause of hyperandrogenic anovulatory infertility and was described more than half a century ago. The underlying cause of this disorder is still uncertain (McCartney and Marshall, 2016).

The diagnostic criteria for PCOS were revised at a consensus conference jointly sponsored by the European society for Human Reproduction and Embryology (ESHRE) and the American society of Reproductive Medicine (ASRM) in Rotterdam, The Netherlands in 2003 (ESHRE/ASRM, 2012). 
The diagnosis now requires the presence of at least two of the following features: Polycystic ovaries Oligoovulation or anovulation Clinical and/or biochemical evidence of androgen excess. Metformin is a biguanide currently used as an oral antihyperglycemic agent and is approved by US food \& Drug Administration to manage type 2 DM. The benefits of metformin on insulin sensitivity have been demonstrated in non-DM women with PCOS (George and Copeland, 2013).

The use of metformin in cases of PCOS is associated with increased menstrual cyclisity, improved ovulation and a reduction in circulating androgen levels (Johnson, 2014).

Clomiphene citrate (CC) this compound has had a remarkably sustained career as the first-line treatment for women with absent or irregular ovulation due to hypothalamic-pituitary dysfunction associated with normal basal levels of endogenous estradiol (WHO groupit) (Nahuis et al., 2013).

$\mathrm{CC}$ was the first medication capable of inducing ovulation and as such created a welcome revolution in the treatment of infertility associated with anovulation (Melo et al., 2015).

The aim of work was to compare the efficacy of clomiphene citrate alone and combined clomiphene citrate and metformin as first line therapy for induction of ovulation and achievement of pregnancy in infertile women due to PCOS.

\section{PATIENTS AND METHODS}

This prospective study was done on 60 infertile women who were recruited from the infertility outpatient clinic of Ghamra Military hospital. All women were diagnosed as anovulatory PCOS.

An informed written consent was taken from each patient after explaining all procedures and steps of the study.

All patients had the following inclusion criteria: Primary infertility, age between 18 and 39 years, PCOS as diagnosed by at least two out of three of the following (according to the American society of reproductive medicine):

Clinical or biochemical evidence of androgen excess, oligo and/or anovulation, ultrasound appearance of the ovaries shows more than 12 follicles In each ovary each measures $2: 9 \mathrm{~mm}$.

Impaired renal or liver functions, contraindication or known allergy to the study medications, morbid obesity (BMI exceeded $35 \mathrm{~kg} / \mathrm{m} 2$ ), diabetes mellitus, hyper or hypo-thyroidism, hyperprolactinemia, ovarian cyst $>6 \mathrm{~cm}$, uterine and adenxal pathology e.g. leiomyomata were excluded from the study.

The following was done to all patients: History taking, general, abdominal and pelvic examinations and pelvic ultrasound.

Weight and height measurement and body mass index (BMI) calculation (BMI=weight/ height in meters2), and venous blood samples were obtained for measurements of mid luteal serum progesterone (normal: more than $3 \mathrm{ng} / \mathrm{ml}$ ), thyroid function tests, FSH (normal: 3-10 $\mathrm{mIU} / \mathrm{ml}$ ), LH (normal: less than 7 $\mathrm{mIU} / \mathrm{ml}$ ) and serum Prolactin. 
The patients were divided into two equal groups:

Group A were given Clomiphene citrate for induction of ovulation started from day 2 of the cycle for 5 days and Metformin (Cidophage) $500 \mathrm{mg}$ two times daily then follow up by folliculometry.

Group B were given Clomiphene Cirate only for induction of ovulation started from day 2 of the cycle for 5 days then follow and up by folliculometry.

The drugs administration was continued in six cycles for all women except who got pregnant.

All cases were followed up for 6 cycles by transvaginal ultrasound folliculometry to document ovulation. Each lady had to evacuate the urinary bladder and transvaginal ultrasound was done.

Transvaginal ultrasound was performed using the 5-7.5 MHZ transvaginal probe of sonoace 8800 , Medison, Korea.

Ultrasound was done starting from the day 10 of the cycle and repeated according to the size of the follicles. Follicles measure more than $18 \mathrm{~mm}$ were considered mature follicles.

The following measures were done for all patients:

- Endometrial thickness in $(\mathrm{mm})$ at the greatest diameter perpendicular to the midsagittal plane in the fundal region including both layers of the endometrial cavity.

- Diameter of the growing follicle.

- Number of growing follicle

Evidence of failure to respond to induction was documented by failure of follicular maturation.

TVS was done one week after missed period for diagnosis of pregnancy by detection of gestational sac.

As regard the side effects of the drugs, the drugs were generally tolerated,

No cases of OHSS were detected.

\section{Statistical analysis:}

Data were statistically described in terms of mean \pm standard deviation $( \pm$ $\mathrm{SD}$ ), median and range, or frequencies (number of cases) and percentages when appropriate. Comparison of numerical variables between the study groups was done using one way analysis of variance (ANOVA) test. For comparing categorical data, Chi square (x3) test was performed. Exact test was used instead when the expected frequency was less than 5. p values less than 0.05 was considered statistically significant. All statistical calculations were done using computer program SPSS (Statistical Package for the Social Science; SPSS Inc., Chicago, IL, USA) release 15 for Microsoft Windows (2006).

\section{RESULTS}

In the present study, 60 patients were recruited and equally divided into 2 groups. Each one included 30 patients.
The first group was given Clomiphene citrate + Metformin and the second group were Clomiphene Citrate alone. 
There were no statistically significant differences between both groups as regard

pregnancy rate (Table 1).

Table (1): Comparison of both groups as regard pregnancy rate

\begin{tabular}{|c|c|c|c|}
\hline \multirow{2}{*}{$\begin{array}{ll}\text { Parameter } & \text { Groups } \\
\end{array}$} & Clomiphene citrate & Clomiphene citrate & \multirow{2}{*}{$\begin{array}{l}\chi^{2} \\
P\end{array}$} \\
\hline & +Metformin & & \\
\hline Pregnancy rate & $7 / 30$ & $5 / 30$ & \multirow{2}{*}{0.747} \\
\hline & $(23.3 \%)$ & $(16.6 \%)$ & \\
\hline
\end{tabular}

CC+Metformin group reported 53.3\% ovulation at the first cycle after treatment, decreased to $50.0 \%$ at the second cycle, and still $50.0 \%$ at the third cycle, then increased to $60.0 \%$ at the fourth cycle, decreased to $43.3 \%$ at the fifth cycle and increased to $53.3 \%$ at the sixth cycle. On the other hand, CC reported $43.3 \%$ ovulation after treatment at the first cycle which increased to $56.7 \%$ at the second cycle, then decreased to $33.3 \%$ at the third cycle, then increased to $60.0 \%$ at the fourth cycle, then decreased to $43.3 \%$ at the fifth cycle and increased to $56.7 \%$ at the sixth cycle.

$\mathrm{CC}+$ Metformin achieved a cumulative rate of ovulation of $51.6 \%$, while $\mathrm{CC}$ achieved $48.8 \%$ so there was no statistically significant difference between both groups as regard cumulative rate of ovulation (Table 2)

Table (2): Effect of treatment on ovulation in both groups. Data are presented as number (frequency)

\begin{tabular}{|l|c|c|c|}
\hline \multicolumn{1}{|c|}{ Ovulation } & CC+Metformin & CC & P \\
\hline Ovulation after one month treatment & $16(53.3 \%)$ & $13(43.3 \%)$ & 0.60 \\
\hline $\begin{array}{l}\text { Ovulation after two months } \\
\text { treatment }\end{array}$ & $15(50.0 \%)$ & $17(56.7 \%)$ & 0.79 \\
\hline $\begin{array}{l}\text { Ovulation after three months } \\
\text { treatment }\end{array}$ & $15(50.0 \%)$ & $10(33.3 \%)$ & 0.29 \\
\hline $\begin{array}{l}\text { Ovulation after four months } \\
\text { treatment }\end{array}$ & $18(60.0 \%)$ & $18(60.0 \%)$ & 1.0 \\
\hline $\begin{array}{l}\text { Ovulation after five months } \\
\text { treatment }\end{array}$ & $13(43.3 \%)$ & $13(43.3 \%)$ & 1.0 \\
\hline Ovulation after 6 months treatment & $16(53.3 \%)$ & $17(56.7 \%)$ & 1.0 \\
\hline Cumulative ovulation & $93(51.6 \%)$ & $88(48.8 \%)$ & 0.69 \\
\hline
\end{tabular}

\section{DISCUSSION}

Polycystic ovary syndrome (PCOS), also called hyperandrogenic anovulation (HA), is one of the most common endocrine disorders among females. PCOS has a diverse range of causes that are not entirely understood, but there is strong evidence that it is largely a genetic disease (Diedrich et al., 2011).
PCOS produces symptoms in approximately $5 \%$ to $10 \%$ of women of reproductive age (approximately 12 to 45 years old). It is thought to be one of the leading causes of female subfertility and the most frequent endocrine problem in women of reproductive age (Roe and Dokras, 2011).

The most common immediate symptoms are anovulation, excess 
androgenic hormones and insulin resistance. Anovulation results in irregular menstruation, amenorrhea and ovulationrelated infertility. Hormone imbalance generally causes acne and hirsutism. Insulin resistance is associated with obesity, type 2 diabetes and high cholesterol levels (Teede et al., 2010). The symptoms and severity of the syndrome vary greatly among affected women.

Clomiphene citrate is considered firstline therapy for ovulation induction for women with PCOS and infertility (Vause et al., 2010).

Many clinical studies have addressed the impact of metformin treatment on hyperandrogenemia in women with PCOS. Most, but not all, studies have confirmed that metformin treatment since then, for at least 6 months reduces androgen levels in women with PCOS (Sanoee et al., 2011).

Metformin monotherapy, as compared to placebo, has been shown to improve ovulation rates in women with PCOS in randomized controlled trials (RCTs) and cohort studies. However, only few of them had pregnancy as a defined outcome measure (Johnson, 2014).

The results of the present study revealed that both types of treatment were effective in treatment of PCOS patients. No statistically significant difference was found between $(\mathrm{CC}+$ Metformin) group and $\mathrm{CC}$ group as regard ovulation rate. There was a statistically significant decrease in oligomenorrhea after treatment in comparison to their values before treatment in both groups, and CC had nearly equal effects in regulating menstrual cycle.
Lashen (2010), in a randomized controlled trial demonstrated a significantly increased frequency of ovulation with metformin as compared to placebo. This was achieved without any significant changes in the insulin response to glucose challenge after 14 weeks of metformin treatment.

Another study was carried out to assess pregnancy outcome in anovulatory infertility patients diagnosed with polycystic ovary syndrome (PCOS) who were treated with metformin; which revealed that metformin alone in patients with PCOS results in a substantial number of pregnancies, with $69 \%$ of those who ovulated conceived in less than 6 months (Tohma et al., 2019).

In another prospective case control study, Salman et al. (2010) concluded that both metformin and clomiphene citrate can be used as agents for induction ovulation in infertile patients. However, combination of clomiphene citrate and metformin can induce ovulation better than clomiphene alone.

A randomized controlled trial of independent cases and controls was conducted in Saudi Arabia by Ayaz et al. (2013) stated that there was a statistically significant increase in the rates of ovulation and pregnancy in the metformin-clomiphene citrate group as compared with the placebo- clomiphene citrate controls.

Dasari and Pranahita (2009) shows that the therapeutic option with clomiphene and metformin were effective in treating anovulatory infertility in polycystic ovarian syndrome patients more than clomiphene alone. 
The capacity of metformin to attenuate both IR and androgen excess, at least in some patients, has rationalized the investigation of metformin's role in the management of reproductive failure in PCOS women. Metformin either alone or in combination with clomiphene citrate (CC) is a pharmaceutical option for ovulation induction in women with PCOS (Rojas et al. 2014).

Misso et al. (2013) concluded that there is insufficient evidence to establish a difference between Metformin and Clomiphene Citrate in terms of ovulation, pregnancy and live birth.

Our study agreed with another study by Legro et al. (2007) who concluded that $\mathrm{C} / \mathrm{C}(22.5 \%)$ is superior to metformin, but similar to the combination group in achieving live birth rates. They did not observe any difference in the abortion rates between the three groups, and observed a significantly better live birth rate if the $\mathrm{BMI}$ is less than 30 regardless of the treatment option used.

Salman et al. (2010) showed that combination of Clomiphene citrate and metformin can induce ovulation better than clomiphene alone.

The studies that agree with our study Palomba and Nestler (2008) showed no difference in fertility improvement between the combination treatment and CC monotherapy. Also, Misso et al. (2013) concluded that there is insufficient evidence to establish a difference between metformin and clomiphene citrate.

The different results among these clinical studies may be explained by patient hetero-geneity, including differences in genotype, BMI, and circulating androgen levels may account for some of differences.

\section{CONCLUSION}

Both CC+Metformin and $\mathrm{CC}$ alone were effective in treatment of infertility in PCOS patients.

\section{REFERENCES}

1. Ayaz A, Ahvan Y and Farooq MU (2013): Efficacy of combined metfoimin-clomiphene citrate in comparison with clomiphene citrate alone in infertile women with polycystic ovarian syndrome (PCOS). J Med Life, 6(2): 199-201.

2. Dasari P and Pranahita GK (2009): The efficacy of metformin and clomiphene citrate combination compared with clomiphene citrate alone for ovulation induction in infertile patients with PCOS. Journal of Human Reproductive Sciences, 2(1):18.

3. Dennett CC and Simon J (2015): The role of polycystic ovary syndrome in reproductive and metabolic health: overview and approaches for treatment. Diabetes Spectrum, 28(2): 116-20.

4. Diedrich $\mathrm{K}$, Fauser $\mathrm{BC}$ and Bouchard $\mathbf{P}$ (2011): Contemporary genetic technologies and female reproduction. Hum Reprod Update, 17(6):829-47.

5. ESHRE/ASRM-Sponsored PCOS Consensus Workshop Group (2012): Consensus on infertility treatment related to polycystic ovary syndrome. Human Reproduction, 23(3):462-77.

6. George MM and Copeland KC (2013): Current treatment options for type 2 diabetes mellitus in youth: today's realities and lessons from the TODAY study. Current Diabetes Reports, 13(1):72-80.

7. Johnson NP (2014): Metformin use in women with polycystic ovary syndrome. Annals of Translational Medicine, 2(6): 1832.

8. Lashen H (2010): Role of metformin in the management of polycystic ovary syndrome. 
Therapeutic advances in endocrinology and metabolism, 1(3): 117-28.

9. Legro R, Barnhart H, Schlaff W, Carr B, Diamond M, Carson S, Steinkampf M, Coutifaris C, McGovern P, Cataldo N, Gosman G, Nestler J, Giudice L, Leppert $P$ and Myers E (2007): Clomiphene, Metformin, or Both for Infertility or both for infertility in the Polycystic Ovary Syndrome, N Engl J Med., 356 (6): 551-566.

10. McCartney CR and Marshall JC (2016): Polycystic ovary syndrome. New England Journal of Medicine, 375(1):54-64.

11. Melo AS, Ferriani RA and Navarro PA (2015): Treatment of infertility in women with polycystic ovary syndrome: approach to clinical practice. Clinics, 70(11):765-9.

12. Misso M, Costello MF, Garrubba M, Wong JL, Hart R, Rombauts L, Melder A, Norman RJ and Teede H (2013): Metformin versus clomiphene citrate for infertility in non-obese women with PCOS: a systematic review and meta-analysis. Hum Reprod Update, 19:2-11.

13. Nahuis MJ, Weiss NS, van der Veen F, Mol BW, Hompes PG, Oosterhuis J, Lambalk NB, Smeenk JM, Koks CA, van Golde RJ and Laven JS (2013): The MOVIN study: does switching treatment to FSH and/or IUI lead to higher pregnancy rates in a subset of women with world health organization type II anovulation not conceiving after six ovulatory cycles with clomiphene citrate-a randomised controlled trial. BMC Women's Health, 13(1):42-48.

14. Palomba S, Falbo A, Orio F Jr, Tolino A and Zullo F (2008): Efficacy predictors for metformin and clomiphene citrate treatment in anovulatory infertile patients with polycystic ovary syndrome. Fertility and Sterility, 91: 2557-2567.

15. Roe AH and Dokras A (2011): The diagnosis of polycystic ovary syndrome in adolescents. Reviews in Obstetrics and Gynecology, 4(2):45-51.
16. Rojas J, Chávez-Castillo $M$ and Bermúdez V (2014): The role of metformin in metabolic disturbances during pregnancy: polycystic ovary syndrome and gestational diabetes mellitus. International Journal of Reproductive Medicine, 216-233.

17. Salman A, Yaaqoub $\mathbf{N}$ and A1-Kareem I (2010): Clomiphene Citrate Versus Clomiphene Citrate and Metformin For Induction Ovulation In PCOS Infertile Patients, Dept, of Gyn. and Obs., College of Medicine, Tikrit University.

18. Sanoee MF, Neghab $N$, Rabiee $S$ and Amiri I (2011): Metformin therapy decreases hyperandrogenism and ovarian volume in women with polycystic ovary syndrome. Iranian Journal of Medical Sciences, 36(2):90-97.

19. Teede H, Deeks A and Moran L (2010): Polycystic ovary syndrome: a complex conditions with psychological, reproductive and metabolic manifestations those impacts on health across the lifespan. BMC Med., 8:41-55.

20. Tohma YA, Onalan G, Tepeoglu M, Bayraktar N, Colak E, Ozcimen EE and Zeyneloglu HB (2019): Phosphodiesterase 4 inhibitor plus metformin is superior to metformin alone for the treatment of polycystic ovary syndrome: A rat model study. Experimental and therapeutic medicine, 17(5):4013-22.

21. Vause TD, Cheung AP, Sierra S, Claman P, Graham J, Guillemin JA, Lapensée L, Steward S and Wong BC (2010): Ovulation induction in polycystic ovary syndrome. Journal of Obstetrics and Gynaecology Canada, 32(5):495-502. 


\section{تأثير إضافة الميتفورمين إلى سترات الكلوميفين فى تنشيط المبيض

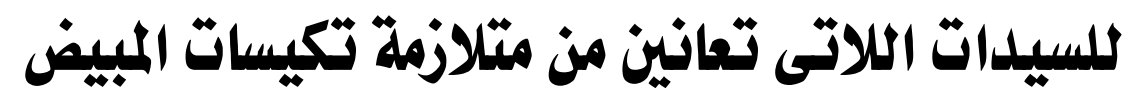 \\ محمد مصطفى، محمد فرحات، محمد عبد الناصر عبد العال} قسم التوليد وأمر اض النساء، كلية الطب، جامعة عين شمس

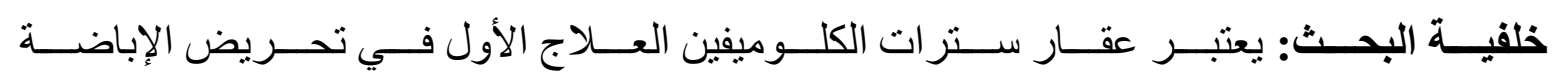

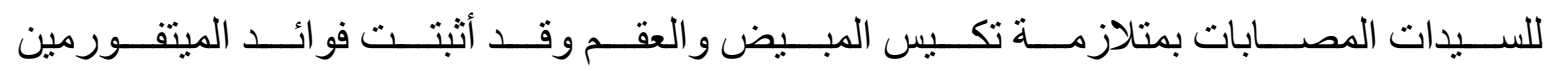

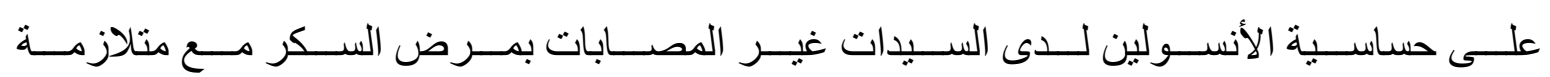
تكيس المبيض.

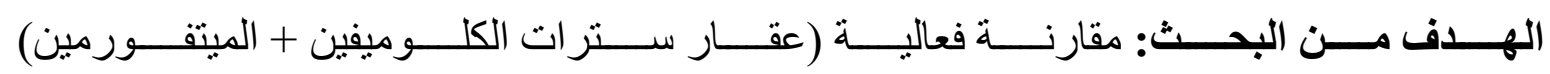
وسترات الكلوميفين وحده في علاج التبويض.

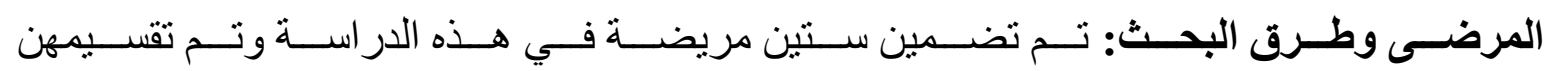

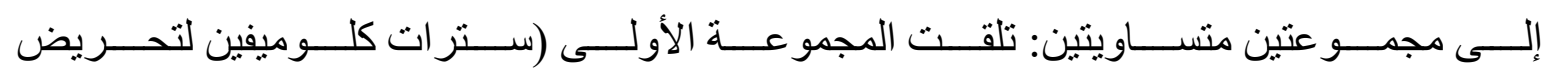

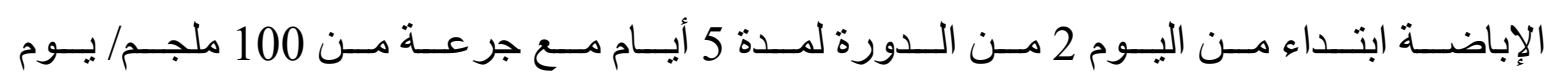

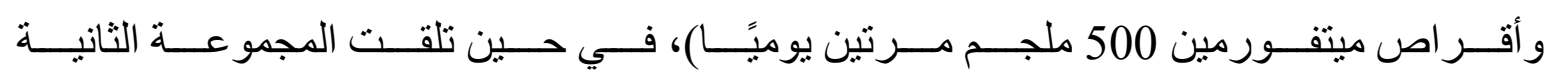

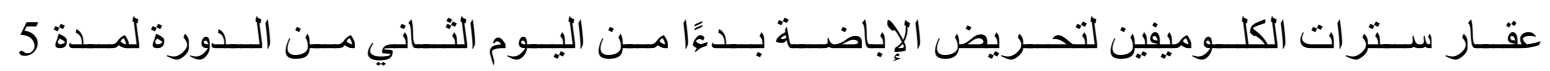
أيام مع جر عة قدر ها 100 مجم / يوم.

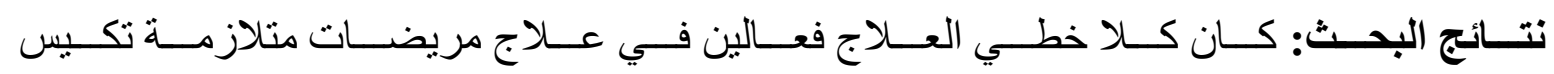

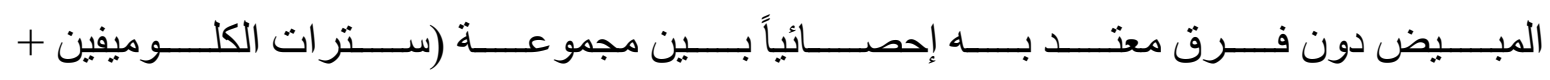

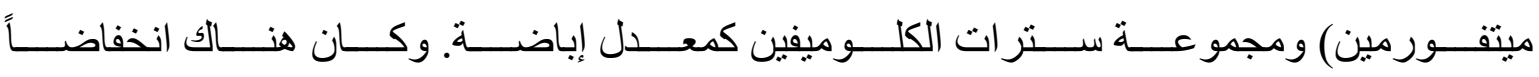

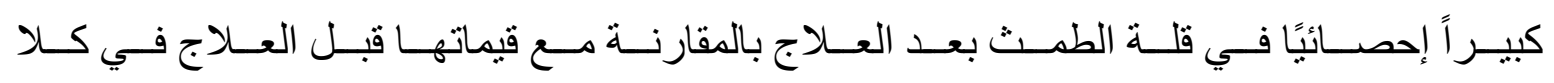
المجمو عتنين.

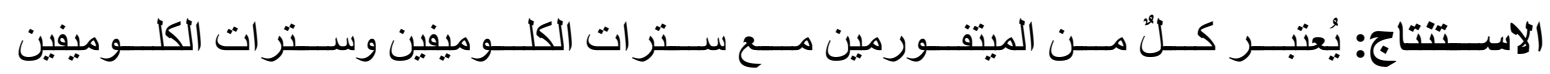
فقط فعالين في علاج العقم عند مرضى متلازمة تكيس المبيض. 